Case Report

\title{
Fungal Malignant Otitis Externa with Facial Nerve Palsy: Tissue Biopsy Aids Diagnosis
}

\author{
Jenny Walton and Chris Coulson \\ Department of Otorhinolaryngology, Queen Elizabeth Hospital Birmingham, Mindelsohn Way, Edgbaston, Birmingham B15 2 WB, UK \\ Correspondence should be addressed to Jenny Walton; jennywalton@doctors.org.uk
}

Received 2 December 2013; Accepted 23 December 2013; Published 5 February 2014

Academic Editors: M.-K. Chen, D. K. Chhetri, C. F. Hwang, and L.-F. Wang

Copyright (c) $2014 \mathrm{~J}$. Walton and C. Coulson. This is an open access article distributed under the Creative Commons Attribution License, which permits unrestricted use, distribution, and reproduction in any medium, provided the original work is properly cited.

Fungal malignant otitis externa (FMOE) is a serious and potentially life-threatening condition that is challenging to manage. Diagnosis is often delayed due to the low sensitivity of aural swabs and many antifungal drugs have significant side effects. We present a case of FMOE, where formal tissue sampling revealed the diagnosis and the patient was successfully treated with voriconazole, in addition to an up to date review of the current literature. We would recommend tissue biopsy of the external auditory canal in all patients with suspected FMOE in addition to routine microbiology swabs.

\section{Introduction}

Malignant otitis externa (MOE) remains a relatively uncommon condition but can lead to serious morbidity or mortality as diagnosis is often delayed leading to initially ineffective treatment [1]. The infection begins in the external auditory canal, typically presenting with severe otalgia and purulent otorrhoea; it can rapidly spread via the ear canal soft tissue to the temporal bone resulting in osteomyelitis and subsequent cranial nerve palsies and intracranial infection. The prevalence of bacterial MOE is not accurately documented [2] and it is unknown whether fungal MOE is a repercussion of unsuccessfully treated bacterial otitis externa or if it represents a de novo presentation of fungal disease.

The most commonly reported pathogen in malignant otitis externa is Pseudomonas aeruginosa [2]. Aspergillus species and Candida albicans have been implicated in fungal MOE. There are 32 previously reported cases of fungal MOE, usually occurring in patients with some form of immunosuppression-typically diabetes, acquired immunodeficiency, or malignancy. We present a case of fungal malignant otitis externa complicated by a facial nerve palsy that proved very difficult to achieve a formal diagnosis.

\section{Case}

An 83-year-old man with type 2 diabetes presented with right sided otalgia and otorrhoea; examination revealed granulation tissue inferiorly in his ear canal at the Osseochondral junction. A clinical diagnosis of malignant otitis externa was made. Pseudomonas aeruginosa was grown on microbiological culture of the discharge, sensitive to ciprofloxacin. His condition was successfully treated over a period of three months with oral and topical ciprofloxacin and he was discharged from clinic pain-free with an otoscopically normal canal.

One year later, he presented with left-sided grade III facial nerve palsy and a painful left ear (note this is the contralateral side to the original presentation). The left ear was initially otoscopically normal. CT and MR imaging demonstrated a left skull base osteomyelitis with involvement of the temporal bone and extension to the clivus with an associated small epidural abscess. Over the next few months, the VII nerve palsy progressed to complete paralysis (grade VI) and was unresponsive to treatment with ciprofloxacin and meropenem. He developed inflammation of his left external canal with an associated otorrhoea. Numerous aural swabs revealed no definitive microbiological diagnosis. 


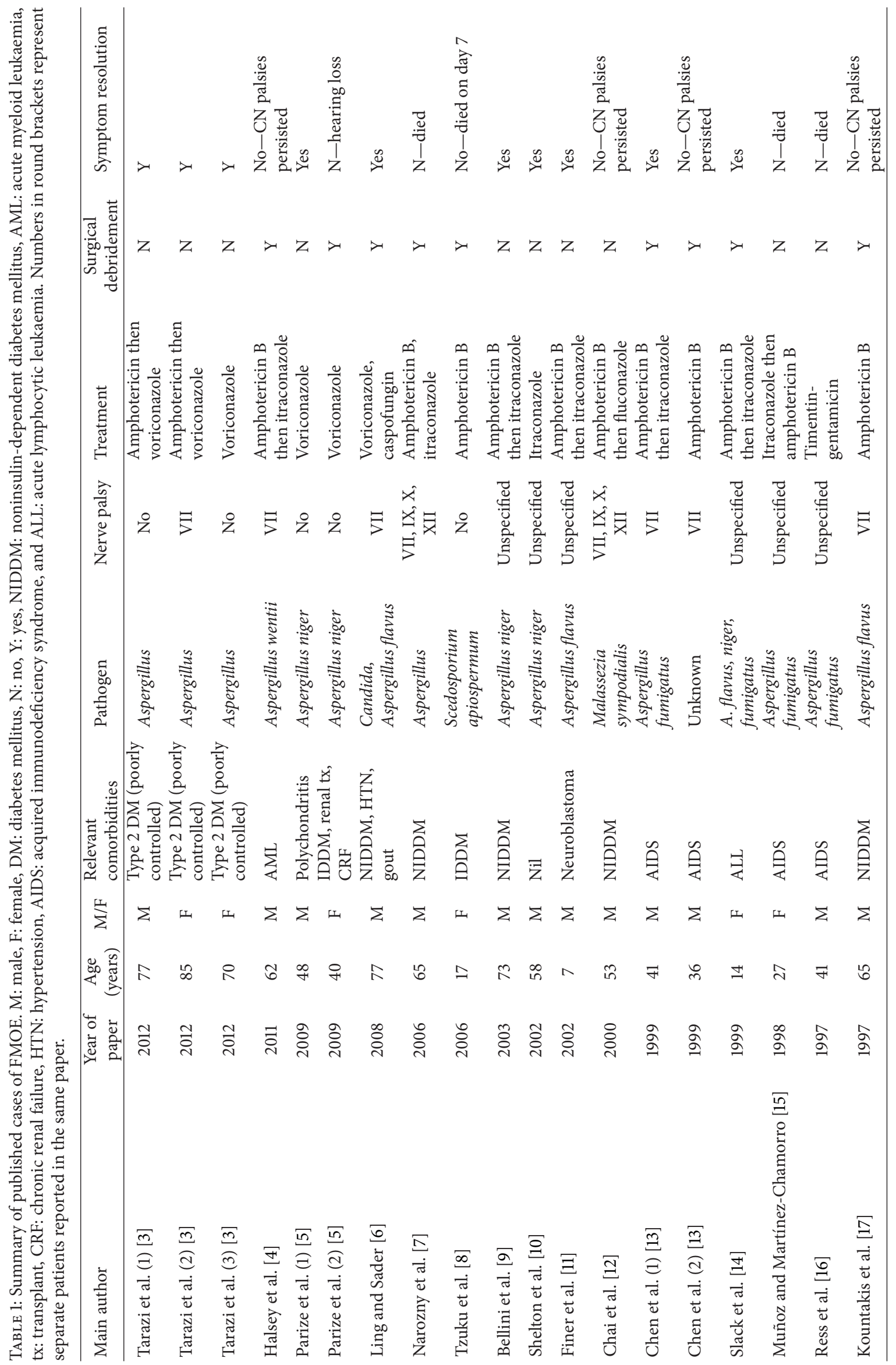




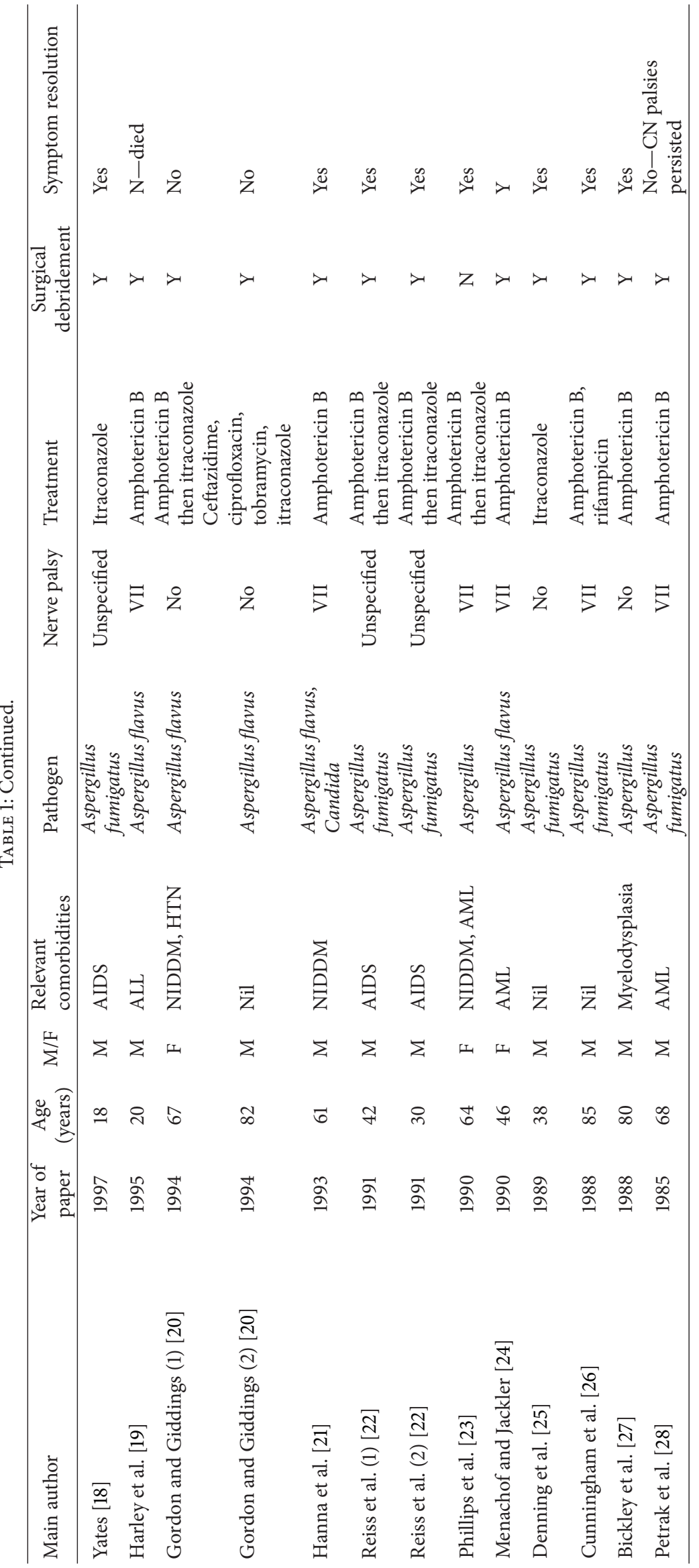


Tissue biopsies were taken directly from the canal and, in contrast to the previous microbiology, Aspergillus flavus was isolated. Treatment was commenced with intravenous voriconazole for 2 weeks, followed by subsequent conversion to oral voriconazole. Within a month of commencing antifungal therapy, he became pain-free and his facial palsy resolved completely. Oral voriconazole therapy was continued for 10 months after resolution of symptoms. The initial plan had been to treat him for 12 months, although the patient developed worsening liver function; hence, the therapy was discontinued.

\section{Discussion}

Cranial nerve palsies are frequently seen in fungal MOE [4]; however, many reported cases have not demonstrated a significant improvement following treatment, possibly due to the delayed isolation of the pathogen and initiation of antifungal treatment. Halsey et al. [4] reported the presence of VII nerve palsy in $75 \%$ of patients with Aspergillus infection, compared with only $34 \%$ in MOE due to Pseudomonas.

Aspergillus fumigatus was thought to be the most common fungal pathogen in MOE [6], with Aspergillus flavus assumed to be a less frequent cause of the condition. However, review of published cases reveals $A$. flavus to be a roughly as prevalent as A. flavus in MOE. A. flavus has been observed to be 100 times more virulent than $A$. fumigatus and has an optimum temperature for growth of $37^{\circ} \mathrm{C}$, which may explain its particular pathogenicity in humans [29].

In MOE, the infection spreads through the fissures of Santorini, small perforations in the cartilaginous floor of the external auditory canal, and then medially until it reaches the skull base [1]. Here, it causes bony destruction and further continues its medial progression triggering cranial nerve palsies with the VII nerve being most commonly affected due to the proximity of the stylomastoid foramen to the ear canal. The presence of a facial nerve palsy has been suggested to represent a poor prognosis in patients with MOE along with coexisting immunosuppression [30]. Table 1 summarizes the cases of fungal MOE (FMOE) present in the literature.

\section{Summary of the Literature}

The mean age of patients in the literature was 52 years with a male: female ratio of $7: 3$. Aspergillus species were the most commonly implicated pathogens. The most frequently occurring comorbidity was diabetes mellitus but haematological malignancy and acquired immunodeficiency were also recognized. $44 \%$ (14/32) of patients were reported to have an associated cranial nerve palsy and 29\% (4/14) of these did not resolve following treatment. There was limited information on total duration of treatment for most of the reported cases. Amphotericin B and itraconazole were favoured for treatment of FMOE in the earlier case reports, whereas voriconazole has played a role in the treatment of the majority of reported cases since 2008. The mortality rate of FMOE was $15 \%(5 / 32)$.
Voriconazole is currently recommended as first line treatment in cases of invasive aspergillosis [31] and its use is increasing since its launch in 2002. The intravenous form is recommended for use in systemically unwell patients, with the oral form being reserved for those who are stable or have improved following initial intravenous treatment. Voriconazole is widely distributed throughout tissues and, in its oral form, is not usually associated with worsening of renal function. This is particularly important as it is often patients with comorbidities affecting renal function such as diabetes, who develop aspergillosis FMOE and therefore require treatment with voriconazole.

The most commonly reported side effects of voriconazole include visual disturbance, particularly to colour vision, abnormal liver function tests, deranged renal function, and electrolyte abnormalities [32]. As noted in the literature, amphotericin B was most frequently used, although it has a significantly poorer side effect profile, including derangement of renal function [5]. Itraconazole and caspofungin have also been used in cases reported in the literature.

Antibiotic therapy for the majority of cases of MOE is guided by the results of aural swabs sent for microbiological culture. Diagnosis of FMOE in our case and other cases in the literature required formal tissue sampling from the external auditory canal in order to identify the pathogen $[4,20,33]$.

The patient in our case presented one year following treatment of bacterial MOE with symptoms in the contralateral ear. Although we found no evidence that the causative organism was the same on both sides, we note one particular case in the literature where the disease spread from one side to the other via the clivus [31].

\section{Conclusion}

We would recommend biopsy of tissue from the external auditory canal in any patient with a presumed diagnosis of MOE in addition to aural swabs. The importance of this is to obtain early confirmation of a fungal pathogen thereby allowing timely treatment to be commenced.

\section{Conflict of Interests}

The authors declare that there is no conflict of interests regarding the publication of this paper.

\section{References}

[1] M. J. Carfrae and B. W. Kesser, "Malignant otitis externa," Otolaryngologic Clinics of North America, vol. 41, no. 3, pp. 537549, 2008.

[2] J. R. Grandis, B. F. Branstetter IV, and V. L. Yu, “The changing face of malignant (necrotising) external otitis: clinical, radiological, and anatomic correlations," Lancet Infectious Diseases, vol. 4, no. 1, pp. 34-39, 2004.

[3] A. E. Tarazi, J. A. Al-Tawfiq, and R. F. Abdi, "Fungal malignant otitis externa: pitfalls, diagnosis, and treatment," Otology \& Neurotology, vol. 33, pp. 769-773, 2012. 
[4] C. Halsey, H. Lumley, and J. Luckit, "Necrotising external otitis caused by Aspergillus wentii: a case report," Mycoses, vol. 54, no. 4, pp. e211-e213, 2011.

[5] P. Parize, M.-O. Chandesris, F. Lanternier et al., "Antifungal therapy of aspergillus invasive otitis externa: efficacy of voriconazole and review," Antimicrobial Agents and Chemotherapy, vol. 53, no. 3, pp. 1048-1053, 2009.

[6] S. S. Ling and C. Sader, "Fungal malignant otitis externa treated with hyperbaric oxygen," International Journal of Infectious Diseases, vol. 12, no. 5, pp. 550-552, 2008.

[7] W. Narozny, J. Kuczkowski, C. Stankiewicz, J. Kot, B. Mikaszewski, and T. Przewozny, "Value of hyperbaric oxygen in bacterial and fungal malignant external otitis treatment," European Archives of Oto-Rhino-Laryngology, vol. 263, no. 7, pp. 680-684, 2006.

[8] A. Tzuku, P. Antonini, S. Ermanni, M. Dolina, E. Passega, and E. Bernasconi, "Necrotizing (Malignant) otitis externa: an unusual localization of mucormycosis," Indian Journal of Medical Microbiology, vol. 24, no. 4, pp. 289-291, 2006.

[9] C. Bellini, P. Antonini, S. Ermanni, M. Dolina, E. Passega, and E. Bernasconi, "Malignant otitis externa due to Aspergillus niger," Scandinavian Journal of Infectious Diseases, vol. 35, no. 4, pp. 284-288, 2003.

[10] J. C. Shelton, P. J. Antonelli, and R. Hackett, "Skull base fungal osteomyelitis in an immunocompetent host," Otolaryngology, vol. 126, no. 1, pp. 76-78, 2002.

[11] G. Finer, D. Greenberg, E. Leibovitz, A. Leiberman, I. Shelef, and J. Kapelushnik, "Conservative treatment of malignant (invasive) external otitis caused by Aspergillus flavus with oral itraconazole solution in a neutropenic patient," Scandinavian Journal of Infectious Diseases, vol. 34, no. 3, pp. 227-229, 2002.

[12] F. C. Chai, K. Auret, K. Christiansen, P. W. Yuen, and D. Gardam, "Malignant otitis externa caused by malassezia sympodialis," Head \& Neck, vol. 22, pp. 87-89, 2000.

[13] D. Chen, A. K. Lalwani, J. W. House, and D. Choo, "Aspergillus mastoiditis in acquired immunodeficiency syndrome," American Journal of Otology, vol. 20, no. 5, pp. 561-567, 1999.

[14] C. L. Slack, D. W. Watson, M. J. Abzug, C. Shaw, and K. H. Chan, "Fungal mastoiditis in immunocompromised children," Archives of Otolaryngology, vol. 125, no. 1, pp. 73-75, 1999.

[15] A. Muñoz and E. Martínez-Chamorro, "Radiology in focus. Necrotizing external otitis caused by Aspergillus fumigatus: computed tomography and high resolution magnetic resonance imaging in an AIDS patient," Journal of Laryngology and Otology, vol. 112, no. 1, pp. 98-102, 1998.

[16] B. D. Ress, M. Luntz, F. E. Telischi, T. J. Balkany, and M. L. H. Whiteman, "Necrotizing external otitis in patients with AIDS," Laryngoscope, vol. 107, no. 4, pp. 456-460, 1997.

[17] S. E. Kountakis, J. V. Kemper Jr., C. Y. J. Chang, D. J. M. DiMaio, and C. M. Stiernberg, "Osteomyelitis of the base of the skull secondary to Aspergillus," American Journal of Otolaryngology, vol. 18, no. 1, pp. 19-22, 1997.

[18] P. D. Yates, "Aspergillus mastoiditis in a patient with acquired immunodeficiency syndrome," Journal of Laryngology and Otology, vol. 111, no. 6, pp. 560-561, 1997.

[19] W. B. Harley, J. S. Dummer, T. L. Anderson, and S. Goodman, "Malignant external otitis due to Aspergillus flavus with fulminant dissemination to the lungs," Clinical Infectious Diseases, vol. 20, no. 4, pp. 1052-1054, 1995.
[20] G. Gordon and N. A. Giddings, "Invasive otitis externa due to Aspergillus species: case report and review," Clinical Infectious Diseases, vol. 19, no. 5, pp. 866-870, 1994.

[21] E. Hanna, G. Hughes, I. Eliachar, J. Wanamaker, and W. Tomford, "Fungal osteomyelitis of the temporal bone: a review of reported cases," Ear, Nose and Throat Journal, vol. 72, no. 8, pp. 532-541, 1993.

[22] P. Reiss, R. Hadderingh, L. J. Schot, and S. A. Danner, "Invasive external otitis caused by Aspergillus fumigatus in two patients with AIDS," AIDS, vol. 5, no. 5, pp. 605-606, 1991.

[23] P. Phillips, G. Bryce, J. Shepherd, and D. Mintz, "Invasive external otitis caused by Aspergillus," Reviews of Infectious Diseases, vol. 12, no. 2, pp. 277-281, 1990.

[24] M. R. Menachof and R. K. Jackler, "Otogenic skull base osteomyelitis caused by invasive fungal infection," Otolaryngology, vol. 102, no. 3, pp. 285-289, 1990.

[25] D. W. Denning, R. M. Tucker, L. H. Hanson, and D. A. Stevens, "Treatment of invasive aspergillosis with itraconazole," American Journal of Medicine, vol. 86, no. 6, pp. 791-800, 1989.

[26] M. Cunningham, V. L. Yu, J. Turner, and H. Curtin, "Necrotizing otitis externa due to Aspergillus in an immunocompetent patient," Archives of Otolaryngology, vol. 114, no. 5, pp. 554-556, 1988.

[27] L. S. Bickley, R. F. Betts, and C. W. Parkins, "Atypical invasive external otitis from Aspergillus," Archives of Otolaryngology, vol. 114, no. 9, pp. 1024-1028, 1988.

[28] R. M. Petrak, J. C. Pottage Jr., and S. Levin, "Invasive external otitis caused by Aspergillus fumigatus in an immunocompromised patient," Journal of Infectious Diseases, vol. 151, no. 1, p. 196, 1985

[29] M. T. Hedayati, A. C. Pasqualotto, P. A. Warn, P. Bowyer, and D. W. Denning, “Aspergillus flavus: human pathogen, allergen and mycotoxin producer," Microbiology, vol. 153, no. 6, pp. 1677$1692,2007$.

[30] V. Franco-Vidal, H. Blanchet, C. Bebear, H. Dutronc, and V. Darrouzet, "Necrotizing external otitis: a report of 46 cases," Otology and Neurotology, vol. 28, no. 6, pp. 771-773, 2007.

[31] T. J. Walsh, E. J. Anaissie, D. W. Denning et al., "Treatment of aspergillosis: clinical practice guidelines of the infectious diseases society of America," Clinical Infectious Diseases, vol. 46, no. 3, pp. 327-360, 2008.

[32] G. R. Thompson IIII and J. S. Lewis, "Pharmacology and clinical use of voriconazole," Expert Opinion on Drug Metabolism and Toxicology, vol. 6, no. 1, pp. 83-94, 2010.

[33] Y. Hamzany, E. Soudry, M. Preis et al., "Fungal malignant external otitis," Journal of Infection, vol. 62, no. 3, pp. 226-231, 2011. 


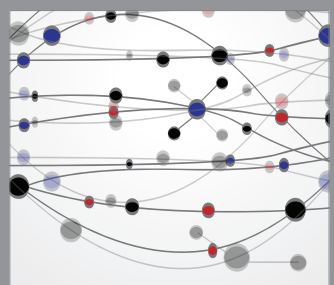

The Scientific World Journal
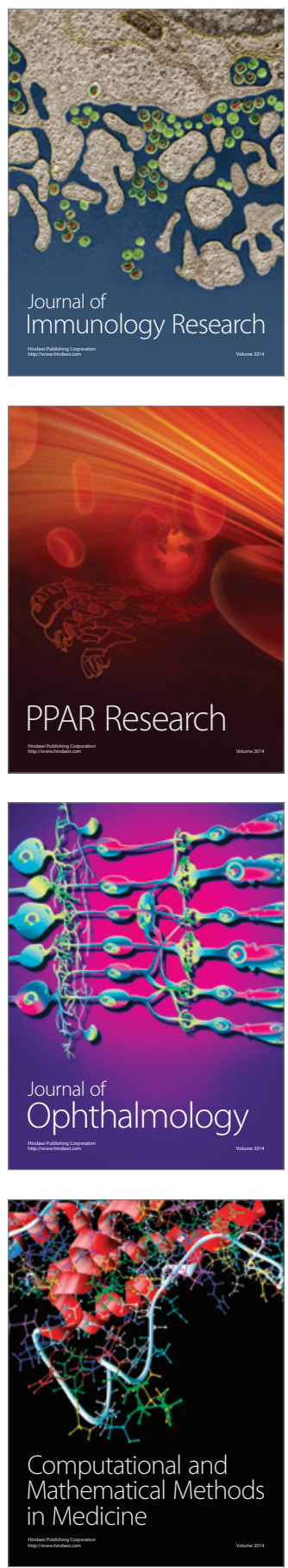

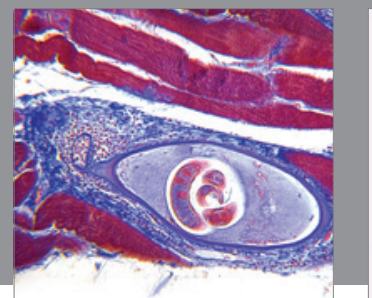

Gastroenterology

Research and Practice
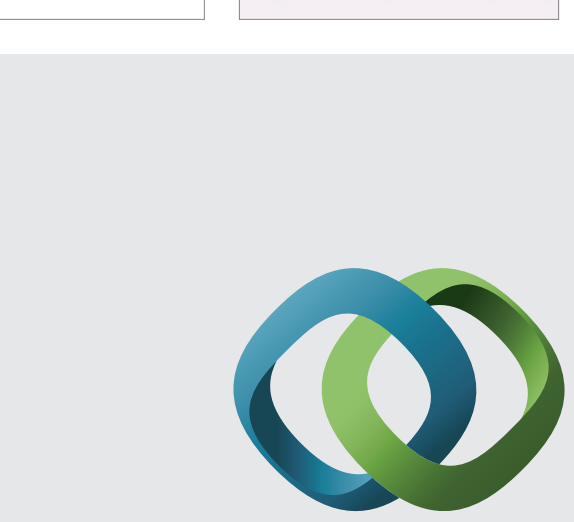

\section{Hindawi}

Submit your manuscripts at

http://www.hindawi.com
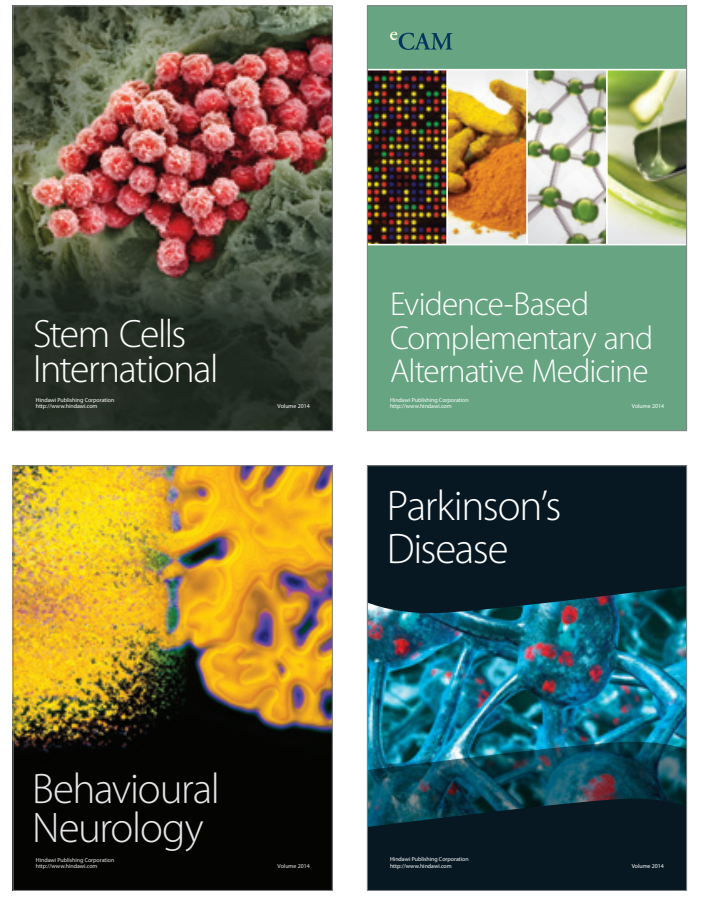
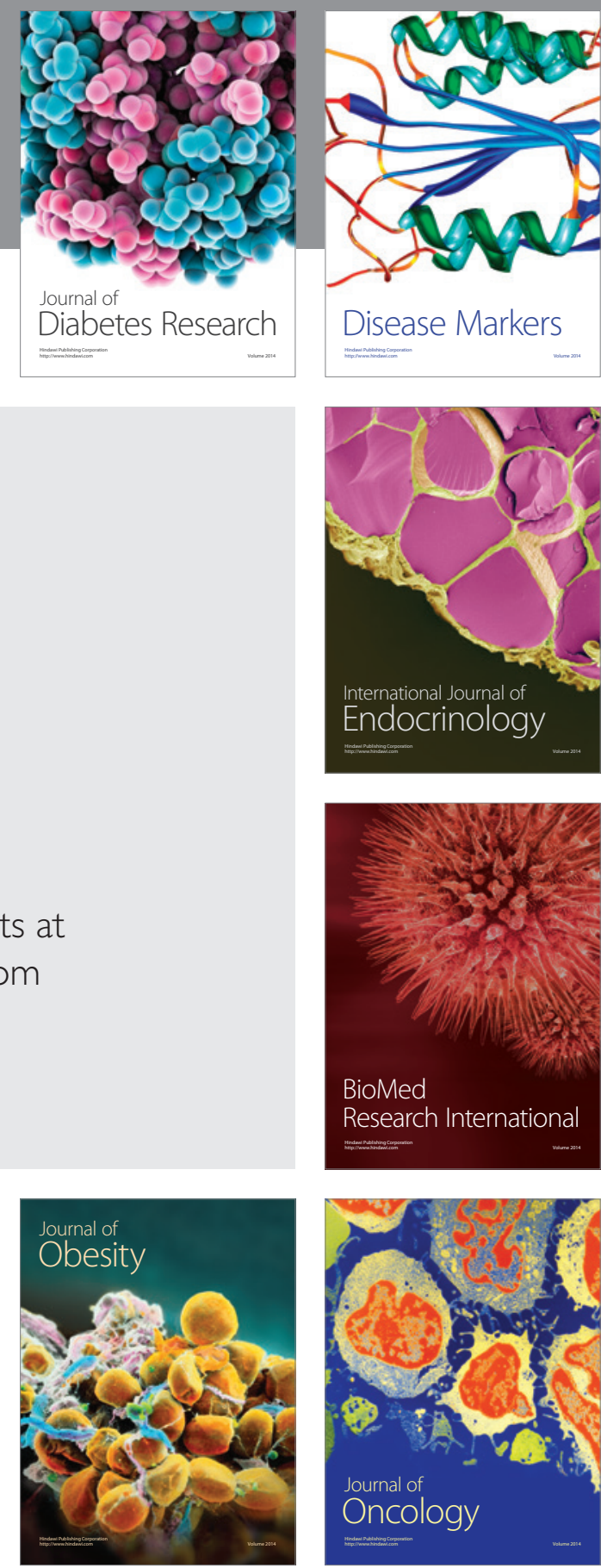

Disease Markers
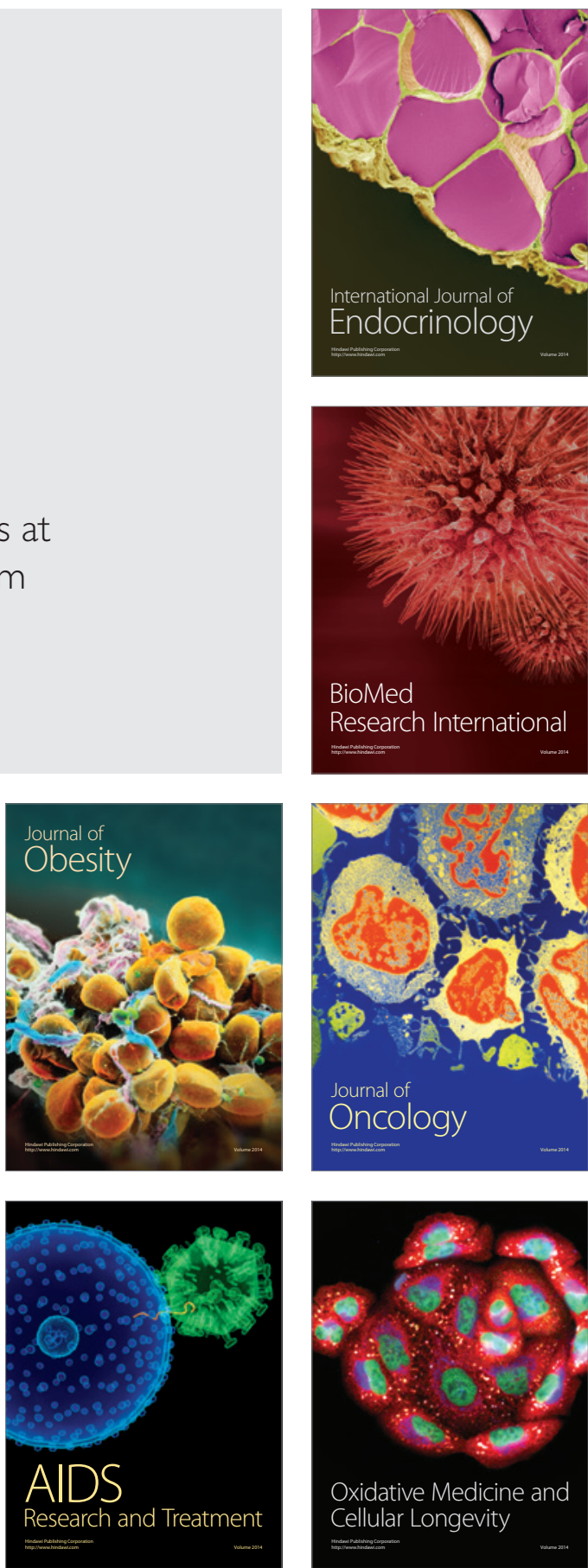